\title{
ORIGINAL ARTICLE \\ Bone loss, low height, and low weight in different populations and district: a meta-analysis between vegans and non-vegans
}

\author{
Jianfeng Li', Ruiyun Zhou², Wei Huang' and Jianjun Wang ${ }^{*}$ \\ 'Department of Spine and Osteology, Zhuhai People's Hospital (Zhuhai Hospital Affiliated with Jinan University), \\ Zhuhai, Guangdong Province, China \\ ${ }^{2}$ Zhuhai Medical Emergency Center, Pre-Hospital Emergency Training Base of Mid-southern China, Zhuhai, \\ Guangdong Province, China
}

\section{Popular scientific summary}

- There are three traditional dietary modes in Europe and the United States (Western, Mediterranean and vegetarian diets). Western dietary patterns are common in the United States, Canada and some countries in northern Europe. The carbohydrate energy supply ratio is only $25 \%$ and the fat energy supply is high, reaching $35 \%$ to $45 \%$, in which the saturated fatty acid accounts for $18 \%$ in Western diets. In addition, the Western diet is high in protein and low in dietary fiber. Western dietary patterns are the main causes of metabolic diseases, such as obesity and type II diabetes in the United States [1].

- The Mediterranean diet (MD), as the name implies, is the diet of inhabitants of the Mediterranean, such as Italy and Greece. The MD is rich in whole grains, beans, fruits, vegetables, nuts and other plant-based foods. Olive oil is the main fat source in the MD, with moderate intake of fish and poultry and a relatively small intake of livestock, sweets and dairy products. Most adults drink wine. The energy supply ratio of the MD is $25 \%$ to $35 \%$, in which the saturated fatty acid accounts for only $7 \%$ to $8 \%$ [2]. In addition, the MD is rich in dietary fiber and a low glycemic index, which can help prevent type II diabetes and cardiovascular disease [3].

- The vegetarian model can be divided into vegan, vegetarian and semi-vegetarian types, depending on the food that is eaten. Veganism refers to the elimination of all animal-based foods in the diet and a substantial intake of fruits, vegetables, beans, nuts and soy protein. The fat supply ratio is appropriate, but an omnivore consumes more polyunsaturated fatty acids than a vegan. Vegetarian diets are similar to those described above, but can include eggs and milk. Semi-vegetarian diets include red meat, poultry and fish, but not more than one time per week [4]. Studies have shown that vegetarians are at risk for a variety of important nutrient deficiencies, including protein, calcium, iron, iodine, vitamin D and vitamin B12, suggesting that a vegetarian diet has a negative impact on bone growth and development [5,6]. For this reason, the current study increased the sample size and improved the test efficiency through a meta-analysis to obtain more authentic and reliable analysis results, which helped to clarify whether a vegetarian diet has negative effects on bone growth and development, and provided evidence-based medicine for clinical diagnosis and treatment.

\section{Abstract}

Objective: The aim of this study was to- conduct a meta-analysis of the association of bone mineral density, height, and weight in different populations between vegans and non-vegans.

Methods: Based on a search of PubMed, Web of Science, MEDLINE, the Cochrane Library, the Wanfang database, and the CNKI database, 14 relevant publications were collected by two researchers. Review Manager 5.3 and Stata 12.0 software were used for data analysis.

Results: The following results were observed in this study: 1) the density of lumbar vertebrae was higher in vegans than in non-vegans (mean difference: $-0.05,95 \% \mathrm{CI}$ : -0.09 to $-0.01, P=0.01$ ); 2 ) hip bone density was higher in non-vegans than in vegans (mean difference: $-0.08,95 \% \mathrm{CI}:-0.14$ to $-0.02, P=0.008$ ); 3 ) weight was higher in non-vegans than in vegans (mean difference: $-2.21,95 \% \mathrm{CI}:-4.05$ to $-0.37, P=0.02$ ); and 4 ) height was higher in non-vegans than in vegans (mean difference: $-1.87,95 \% \mathrm{CI}:-2.52$ to $-1.22, P<0.00001$ ). 
Conclusion: Our study suggests that a vegetarian lifestyle may contribute to bone loss, low height, and low weight based on existing evidence.

Keywords: bone mineral density; height; weight; vegan; meta-analysis

Received: I 8 January 20 19; Revised: I 3 March 2020; Accepted: 9 July 2020; Published: I I September 2020

$\mathrm{T}$ here are three traditional dietary modes in Europe and the United States (Western, Mediterranean, and vegetarian diets). Western dietary patterns are common in the United States, Canada, and some countries in northern Europe. The carbohydrate energy supply ratio is only $25 \%$ and the fat energy supply is high, reaching $35-45 \%$, in which saturated fatty acid accounts for $18 \%$ in Western diets. In addition, the Western diet is high in protein and low in dietary fiber. Western dietary patterns are the main causes of metabolic diseases, such as obesity and type 2 diabetes, in the United States (1).

The Mediterranean diet (MD), as the name implies, is the diet of inhabitants of the Mediterranean, such as Italy and Greece. The MD is rich in whole grains, beans, fruits, vegetables, nuts, and other plant-based foods. Olive oil is the main fat source in the MD, with moderate intake of fish and poultry and a relatively small intake of livestock, sweets, and dairy products. Most adults drink wine. The energy supply ratio of the MD is $25-35 \%$, in which the saturated fatty acid accounts for only 7-8\% (2). In addition, the MD is rich in dietary fiber and has a low glycemic index, which can help prevent type II diabetes and cardiovascular disease (3).

The vegetarian model can be divided into vegan, vegetarian, and semi-vegetarian types, depending on the food that is eaten. Veganism refers to the elimination of all animal-based foods in the diet and a substantial intake of fruits, vegetables, beans, nuts, and soy protein. The fat supply ratio is appropriate, but an omnivore consumes more polyunsaturated fatty acids than a vegan. Vegetarian diets are similar to those described above, but can include eggs and milk. Semi-vegetarian diets include red meat, poultry, and fish, but not more than one time per week (4). Studies have shown that vegetarians are at risk for a variety of important nutrient deficiencies, including protein, calcium, iron, iodine, vitamin $\mathrm{D}$, and vitamin $\mathrm{B} 12$, suggesting that a vegetarian diet has a negative impact on bone growth and development $(5,6)$. For this reason, the current study increased the sample size and improved the test efficiency through a meta-analysis to obtain more authentic and reliable analysis results, which helped clarify whether a vegetarian diet has negative effects on bone growth and development, and provided evidence-based medicine for clinical diagnosis and treatment.

\section{Materials and methods}

\section{Study selection}

By searching PubMed, Web of Science, MEDLINE, the Cochrane Library, the Wanfang database, and the CNKI database for articles published before January 2018, a total of 14 relevant studies were identified. The following keywords were searched: "bone mineral density or bone loss or osteopenia or osteoporosis," "vegans or vegetarians or veganism or lacto-ovo-vegetarian," and(or) "non-vegans or omnivores." To identify titles and abstracts of the relevant literature, reference lists of studies were checked manually. The retrieval time was from January 1991 to March 2018.

\section{Inclusion and exclusion}

All studies included in the meta-analysis met the following criteria: 1) assessment of the bone mineral density (BMD), height, and weight between vegans and non-vegans; 2) case-controlled trial and the controls had no malignant disease; 3) detailed data of studies must be completely provided in the experimental and control groups directly or indirectly; and 4) all studies had similar research methods and purposes. The exclusion criteria were as follows: 1) repeat studies; 2) no control group and research samples $<10 ; 3$ ) incomplete description of data or unclear sample data; 4) animal experimental research; and 5) articles composed of reviews, abstracts, discussions, letters, annotations, and case reports.

\section{Data extraction}

Data were extracted by two reviewers. Extraction of literature included the first author, publication date, country, methods, and basic characteristics of the patients (including age, gender, and quantity).

\section{Quality assessment}

The STROBE scoring system was used to evaluate the quality of the study (7). There are 22 scoring items in the STROBE scoring system. A score of $0-17.5$ is low quality, $17.5-35$ is medium quality, and $35-44$ is high quality. All studies included were of medium- and high-quality research.

\section{Data analysis}

Stata 12.0 and Review Manager 5.3 software were used for the meta-analysis, as follows: 1) the combined BMD, 


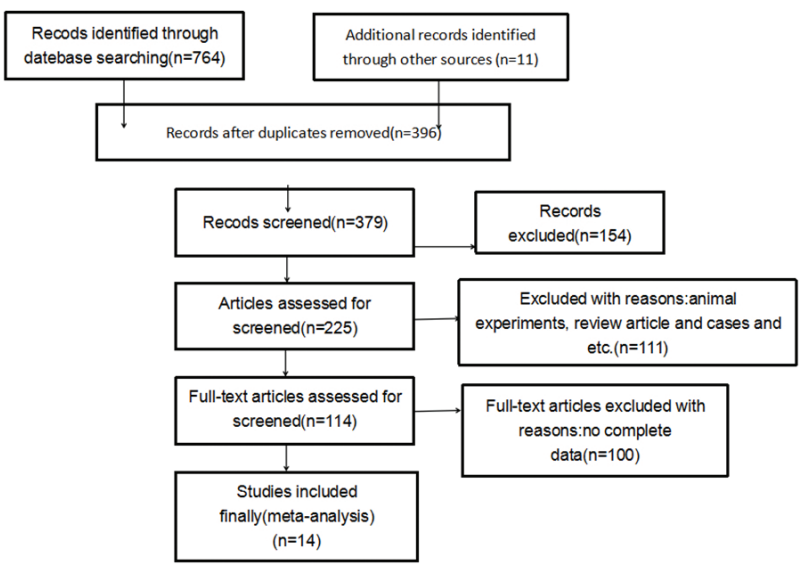

Fig. 1. Literature search flow diagram.

height, and weight and 95\% confidence intervals were calculated; 2) Funnel plot analysis, Begg's test, and Egger's test were used for publication bias; 3 ) heterogeneity between studies was evaluated using a $\chi^{2}$-based $Q$ test and $I^{2}$ test $\left(I^{2}=75-100 \%\right.$, extreme heterogeneity; $I^{2}=50-75 \%$, large heterogeneity; $I^{2}=25-50 \%$, moderate heterogeneity; $I^{2}<25 \%$, no heterogeneity); if there was heterogeneity $\left(I^{2}>50 \%\right)$, the random-effect model was adopted, otherwise the fixed effect model was used; 4) sensitivity analysis was performed by removing one study at a time to compare the difference of pooled effects before and after deleting the study; if the pooled results were reserved after removing the study, it indicated that the results was unstable; 5) subgroup analysis was based on age and populations; and 6) $P<0.05$ was considered statistically significant.

\section{Results}

\section{Characteristics of studies}

Based on the above retrieval methods, 775 relevant studies were selected. After reading the titles and abstracts, and reviewing the full text, 761 studies were excluded. Fourteen case-control studies involving 1,763 subjects were selected for the meta-analysis, as shown in Fig. 1. The main characteristics of the eligible studies are presented in Table 1.

\section{Meta-analysis results}

Comparison of lumbar vertebrae density between vegetarians and non-vegetarians

Fourteen articles (7-21) provided data on 1,763 cases, including 799 vegetarians and 964 non-vegetarians.

1) The heterogeneity test showed statistically significant differences $\left(\chi^{2}\right.$ test $=236.01, P<0.00001$, $I^{2}=94 \%$ ). Therefore, a random-effect model analysis

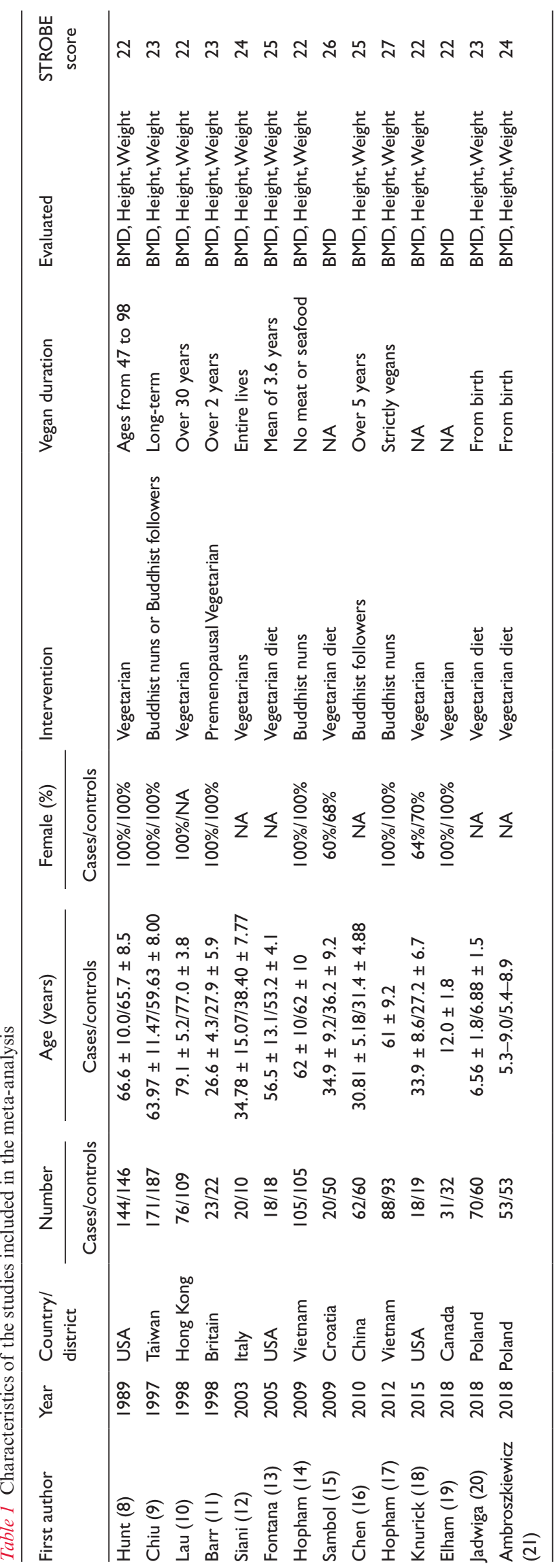




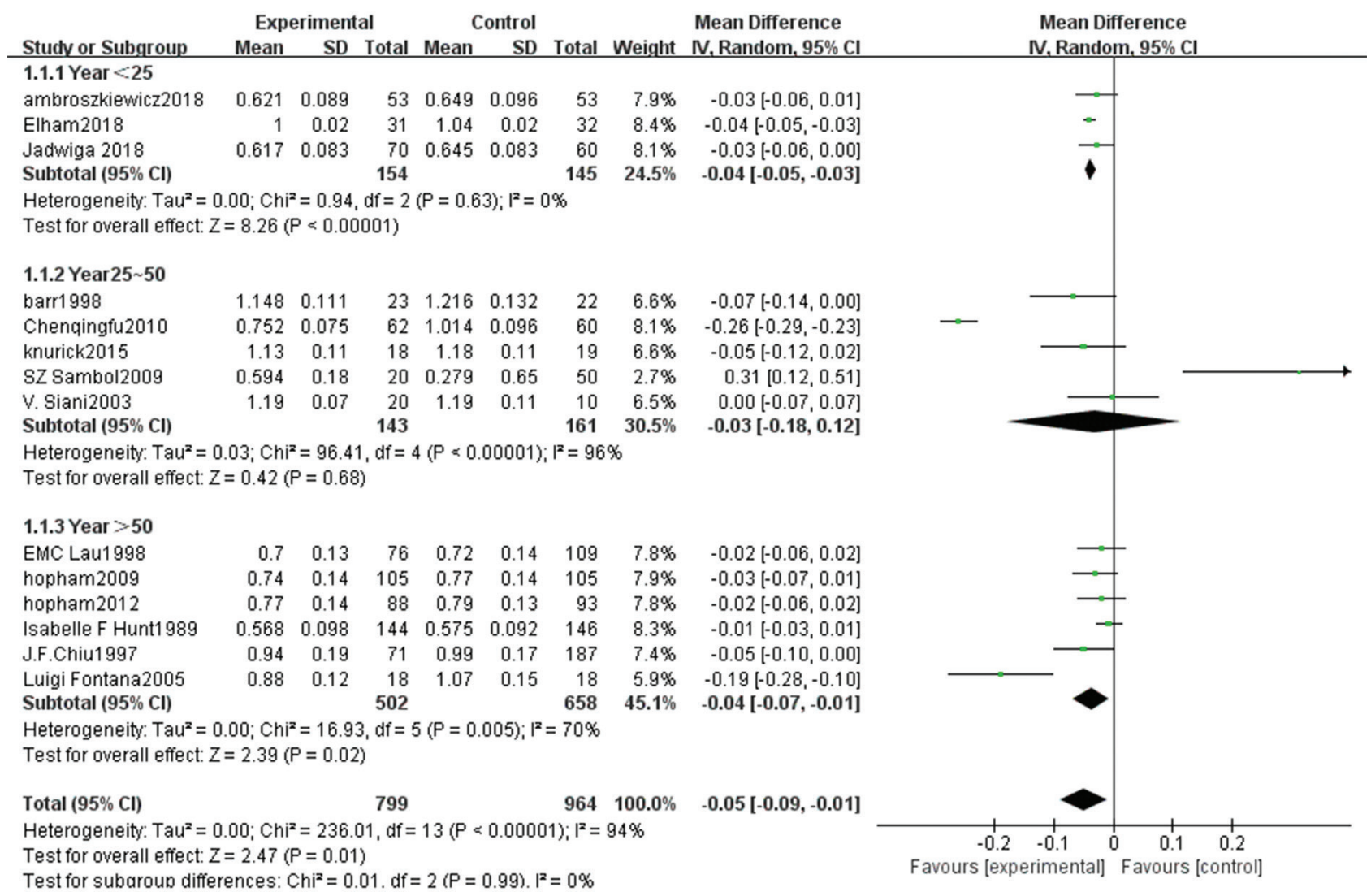

Fig. 2a. Meta-analysis of bone mineral density in spine between different age groups.

was used to show that lumbar vertebral density in the non-vegetarian group was higher than that in the vegetarian group (Fig. 2; mean difference: -0.05 , 95\% CI: -0.09 to $-0.01, P=0.01)$.

2) Sensitivity analysis revealed that the Chen study (16) had a greater impact on the stability of the conclusion (Fig. 2c). After removing the Chen study (16), the lumbar vertebral density of the non-vegetarian group was higher than the vegetarian group (mean difference: $-0.03,95 \% \mathrm{CI}$ : -0.05 to $-0.01, P=0.0006$ ). Heterogeneity analysis was carried out by removing small sample size, which influenced sensitivity. After removing Chen (16), Fontana (13), Knurick (18), Barr (11), Siani (12), and Sambol (15) studies, the heterogeneity was low $\left(\chi^{2}=8.84, P=0.26, I^{2}=21 \%\right)$, and the lumbar vertebral density of the non-vegetarian group was higher than the vegetarian group (mean difference: $-0.03,95 \% \mathrm{CI}$ : $P<0.00001)$.

3) According to the subgroup analysis, compared with the age group, the lumbar vertebrae density of the non-vegetarian diet group $<25$ years or $>50$ years of age was higher than that of the vegetarian diet group (mean difference: $-0.04,95 \% \mathrm{CI}:-0.05$ to $-0.03, P<0.00001$; mean difference: $-0.04,95 \%$
CI: -0.07 to $-0.01, P=0.02$; subgroup difference: $\chi^{2}=0.01, P=0.99, I^{2}=0 \%$; Fig. 2a), and compared with the regional group, the density of lumbar vertebrae in the non-vegetarian group was higher than that in the vegetarian group (mean difference: $-0.05,95 \% \mathrm{CI}$ : -0.09 to $-0.01, P=0.01$; subgroup difference: $\chi^{2}=1.86, P=0.39, I^{2}=0 \%$; Fig. 2b).

Comparison of hip bone density between vegetarians and non-vegetarians

Eight articles (9-10, 13-14, 16-19) provided data on 1,072 cases, including 469 vegetarians and 623 non-vegetarians.

1) The heterogeneity test showed statistical differences $\left(\chi^{2}=244.95, P<0.00001, I^{2}=97 \%\right)$. Therefore, a random-effect model analysis was used to show that hip bone density was higher in the non-vegetarian group than in the vegetarian group (Fig. 3b; mean difference: $-0.08,95 \% \mathrm{CI}$ : -0.14 to $-0.02, P=0.008)$.

2) Sensitivity analysis revealed that the Chen study (16) had a greater impact on the stability of the conclusion. After removing this study, significantly higher hip bone density in the non-vegetarian group than that in the vegetarian group was maintained as the confidence intervals of mean difference among 


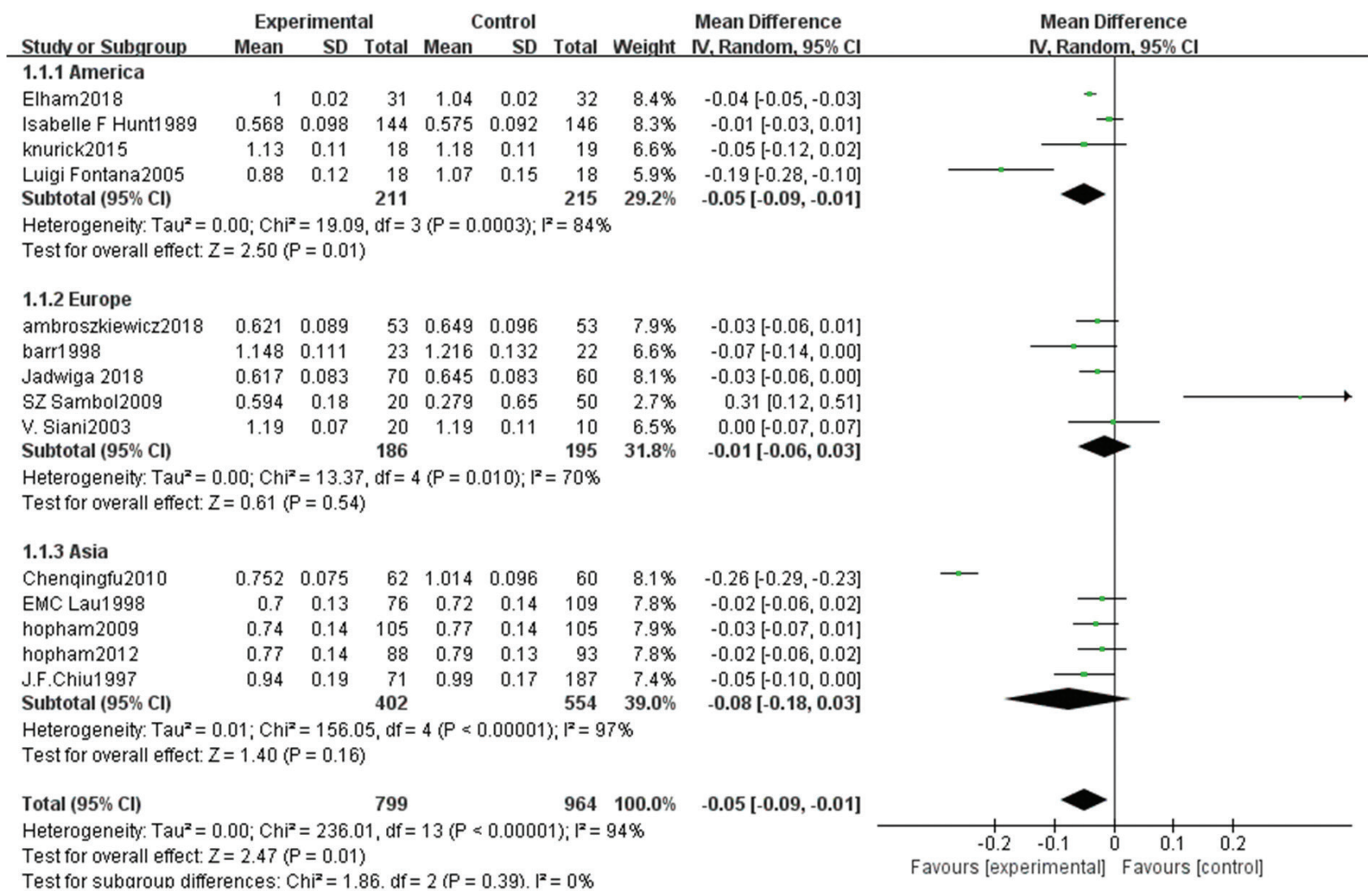

Fig. 2b. Meta-analysis of bone mineral density in spine between different populations.

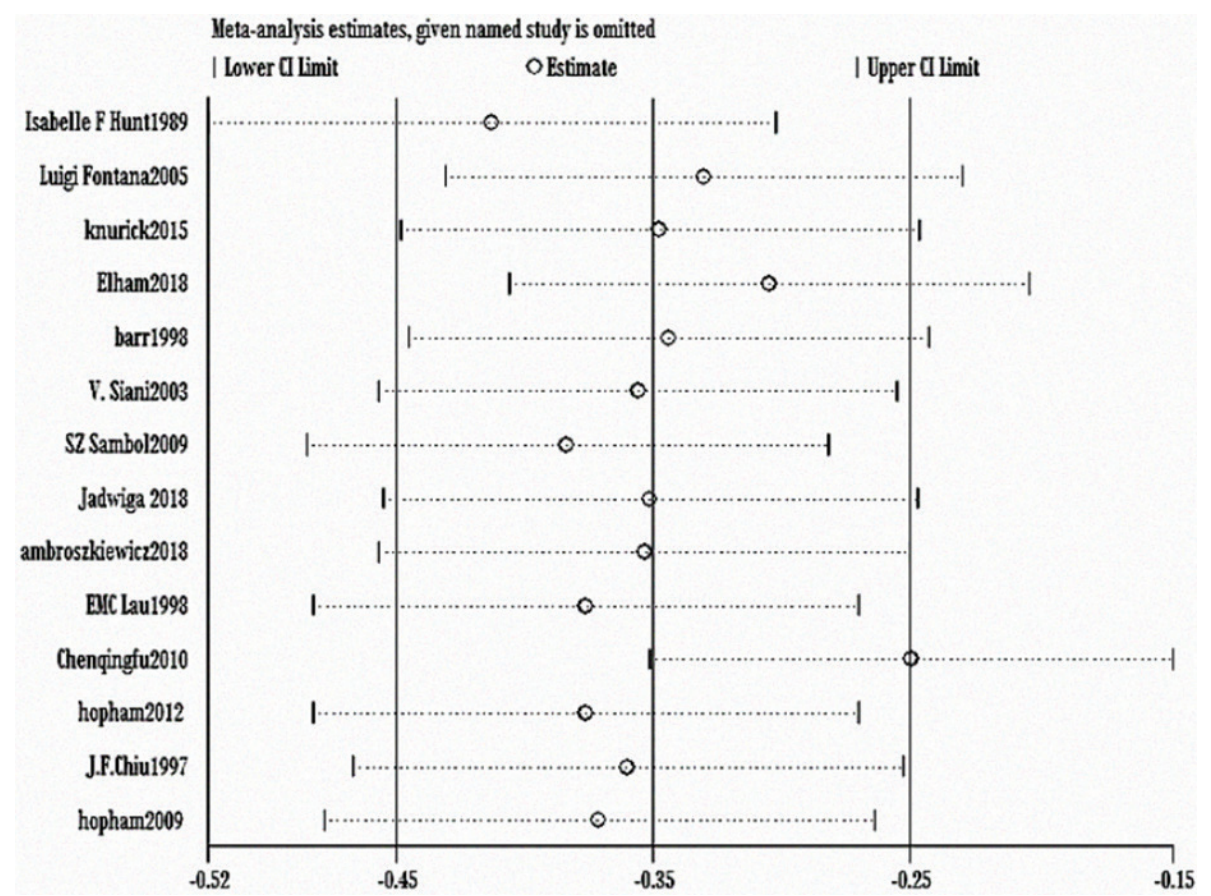

Fig. 2c. Sensitivity analysis of lumbar vertebrae density. 


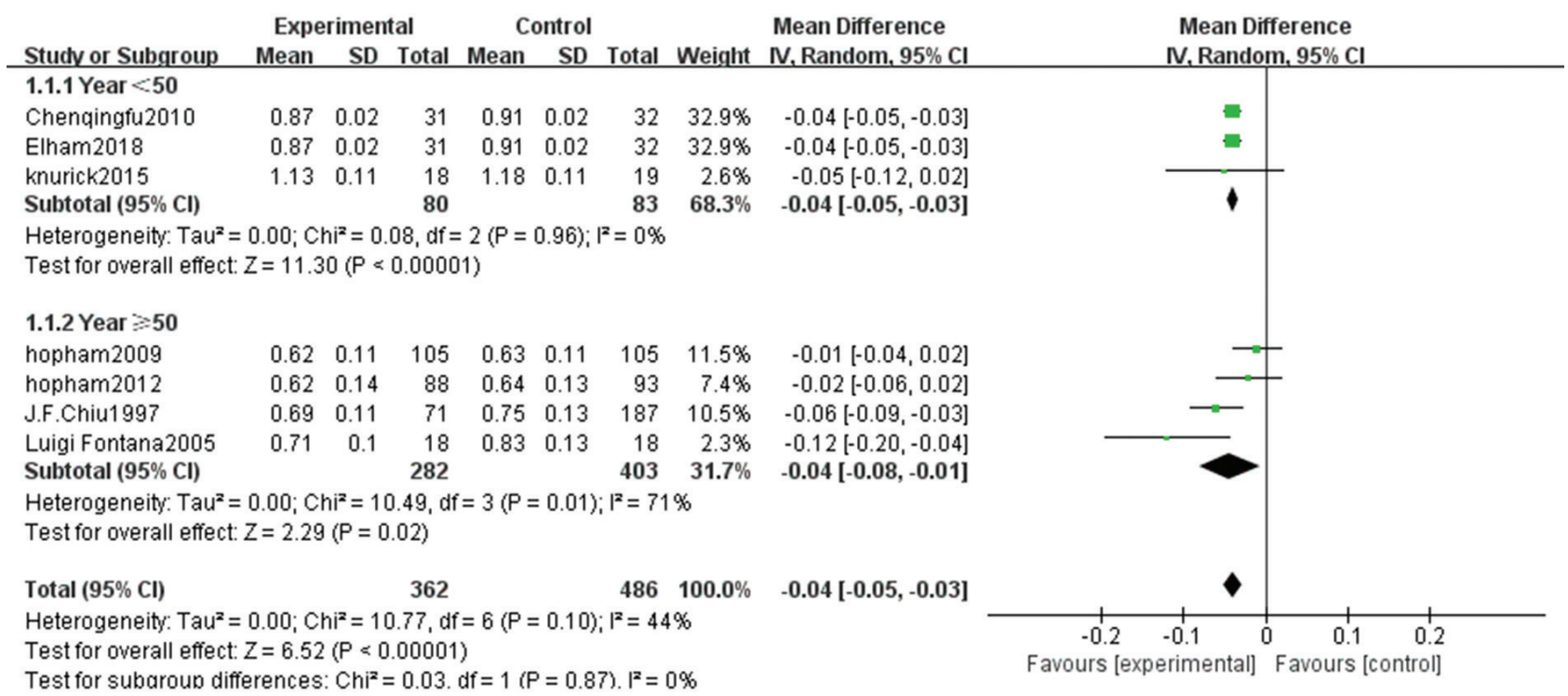

Fig. 3a. Meta-analysis of bone mineral density in hip between different age groups.

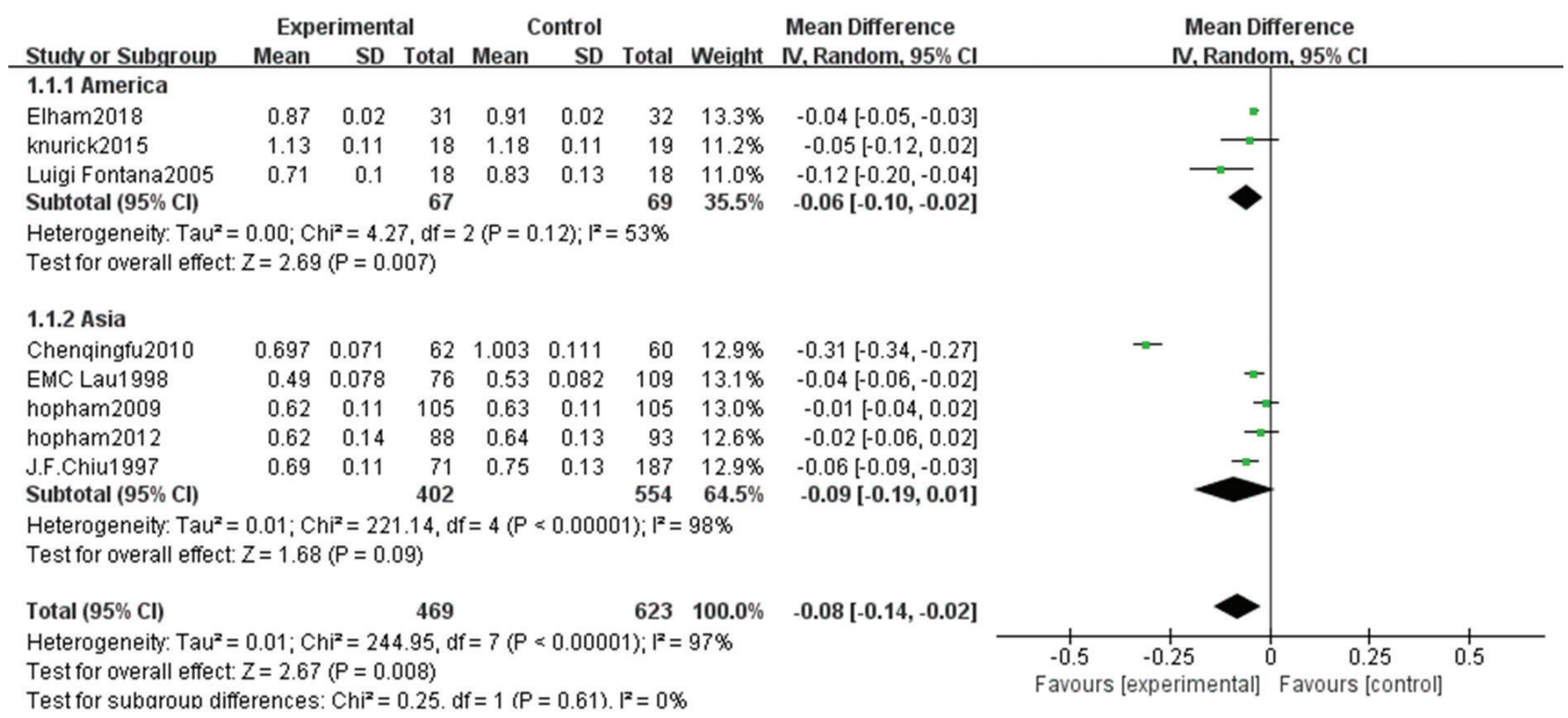

Fig. 3b. Meta-analysis of bone mineral density in hip between different populations.

included studies were closer (Fig. 3c; mean difference: $-0.04,95 \% \mathrm{CI}$ : -0.05 to $-0.03, P<0.0001)$. Heterogeneity analysis was carried out by removing small sample size and influencing sensitivity. After removing the Chen (16), Fontana (13), and Knurick (18) studies, the heterogeneity was low $\left(\chi^{2}=6.24\right.$, $P=0.18, I^{2}=36 \%$ ) and the BMD of the hip in the non-vegetarian group was higher than that in the vegetarian group (mean difference: $-0.04,95 \%$ CI: -0.05 to $-0.03, P<0.00001)$.

3) According to subgroup analysis, compared with the age group, hip bone density in the non-vegetarian group was higher than that in the vegetarian group (mean difference: $-0.04,95 \% \mathrm{CI}:-0.05$ to $-0.03, P<0.00001$; mean difference: $-0.04,95 \% \mathrm{CI}:-0.08$ to $-0.01, P=$ 0.02; subgroup difference: $\chi^{2}=0.03, P=0.87, I^{2}=$ $0 \%$; Fig. 3a), and based on a regional comparison, hip bone density was greater in the non-vegetarian group than the vegetarian group (mean difference: -0.06 , 95\% CI: -0.10 to $-0.02, P=0.007$; subgroup difference: $\chi^{2}=0.25, P=0.61, I^{2}=0 \%$; Fig. 3b).

Weight comparison between vegetarians and non-vegetarians 


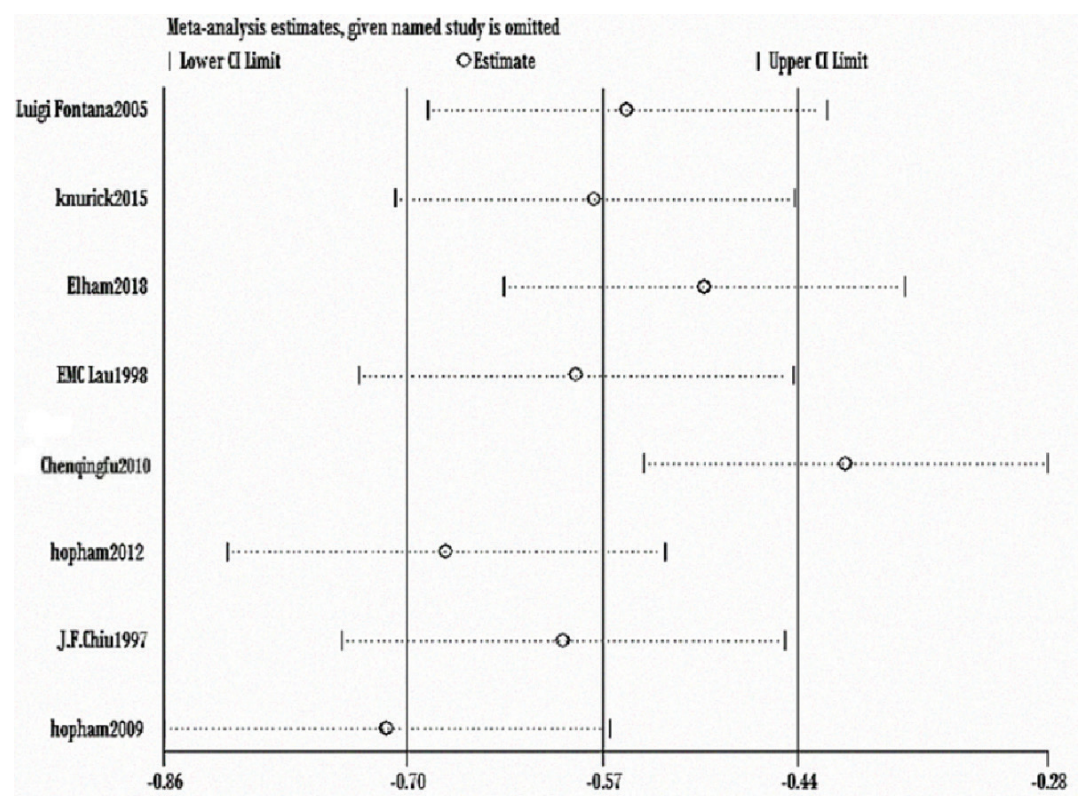

Fig. 3c. Sensitivity analysis of hip bone density.

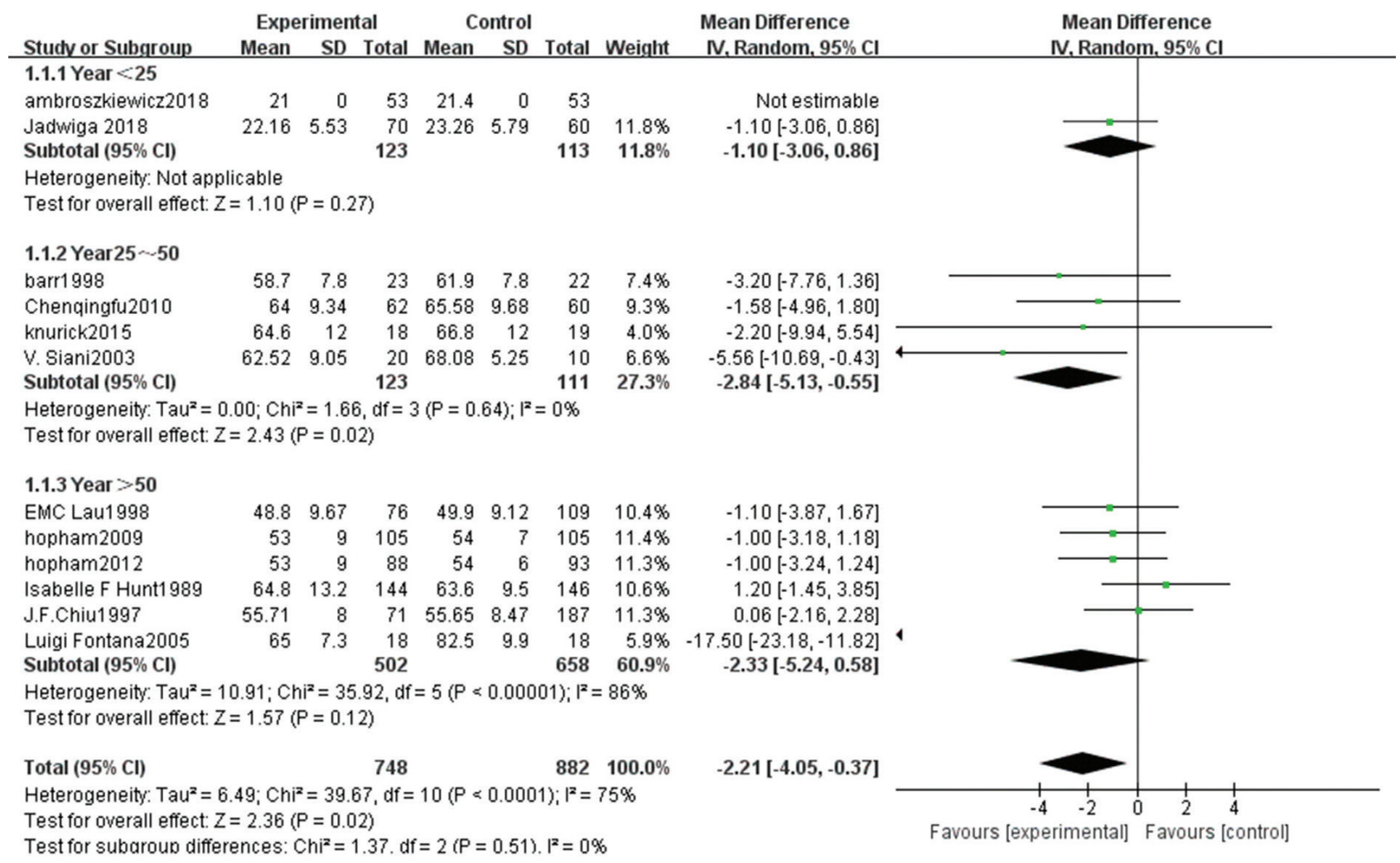

Fig. 4a. Meta-analysis of weight between different age groups.

Twelve articles $(7-14,16-19,21)$ provided data on 1,630 cases, including 748 vegetarians and 882 non-vegetarians.

1) The heterogeneity test showed statistical evidence of differences $\left(\chi^{2}=39.67, P<0.00001, I^{2}=75 \%\right)$.
Therefore, a random-effect model analysis was used to show that the weight of the non-vegetarian group was greater than that of the vegetarian group (Fig. 4; mean difference: $-2.21,95 \% \mathrm{CI}$ : -4.05 to $-0.37, P=0.02)$. 


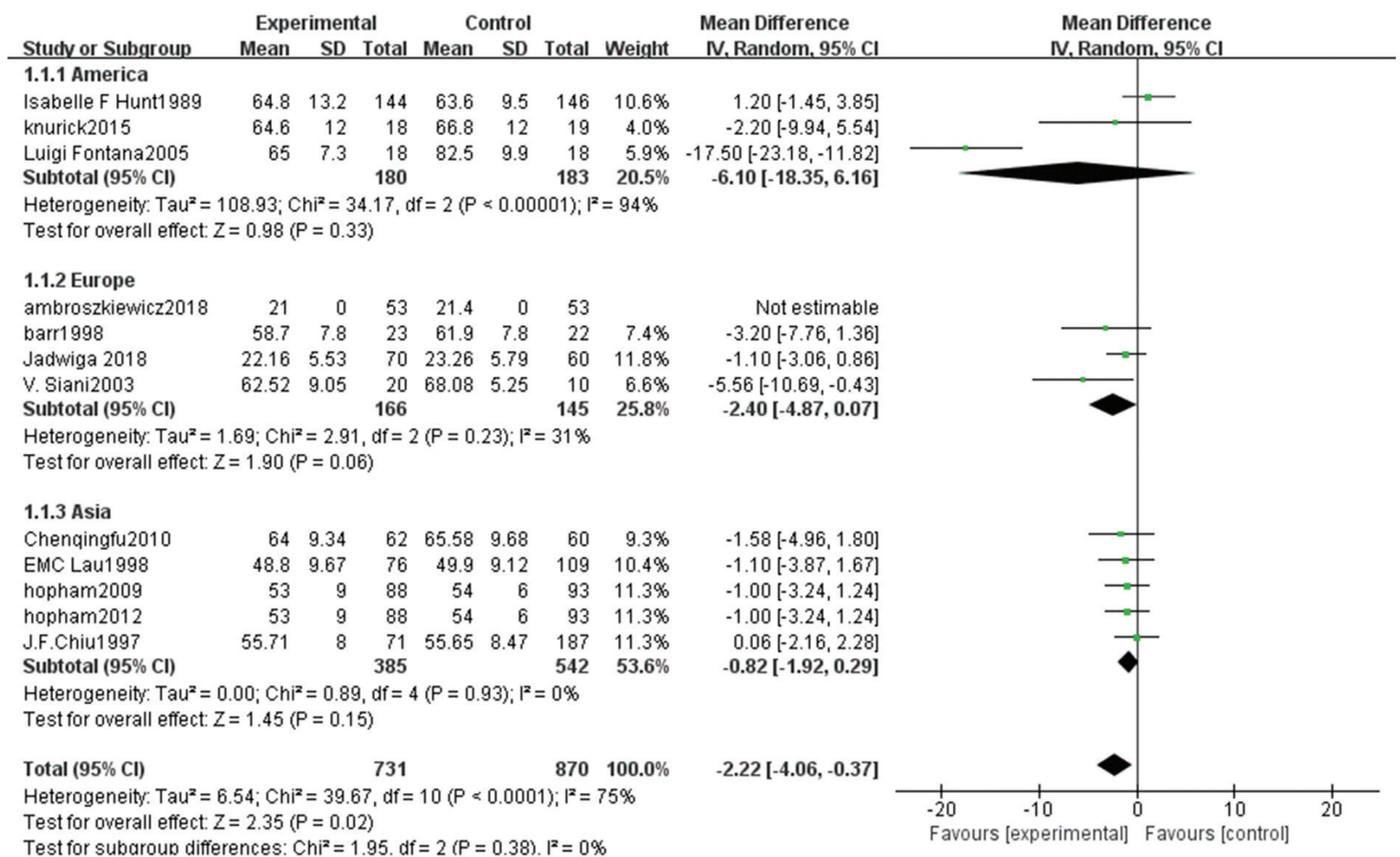

Fig. 4b. Meta-analysis of weight between different populations.

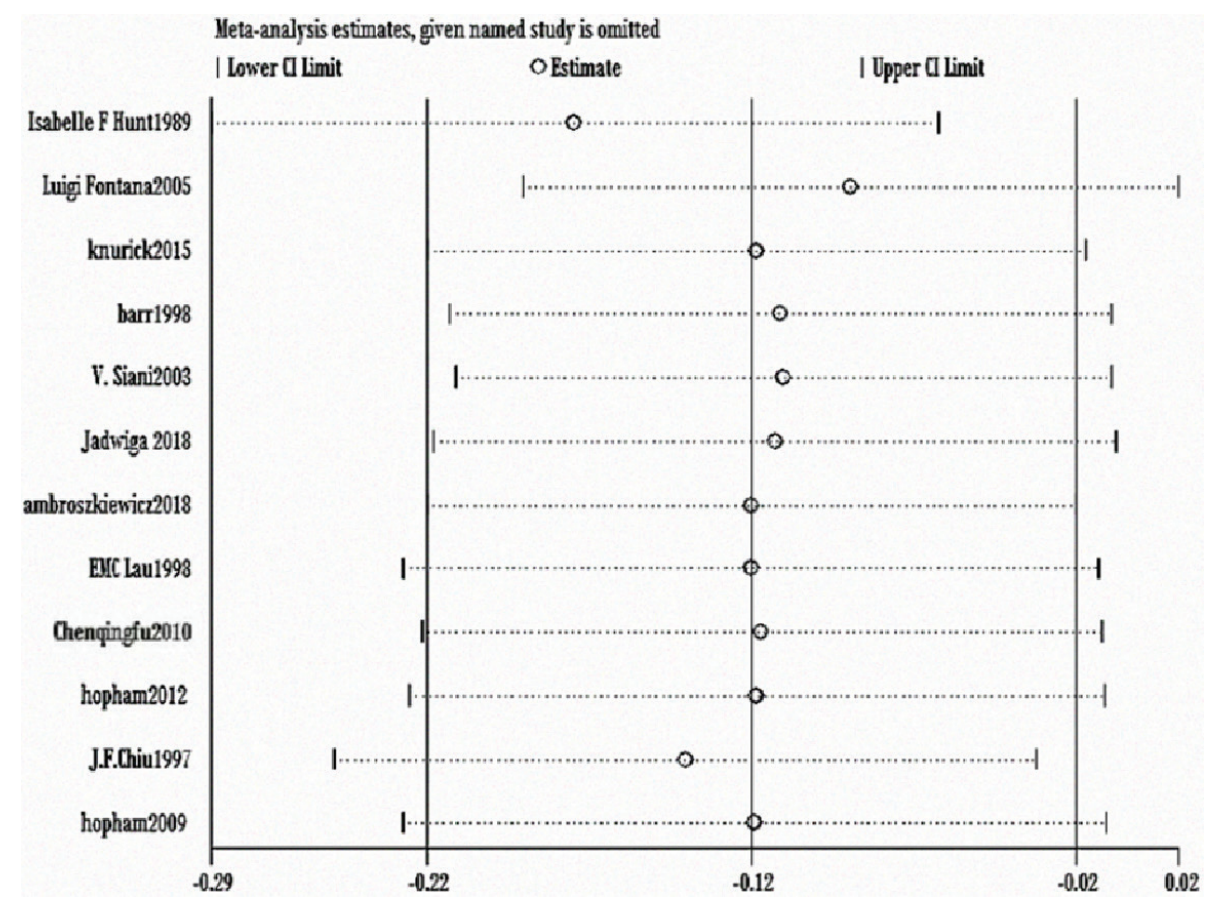

Fig. 4c. Sensitivity analysis of body weight. 


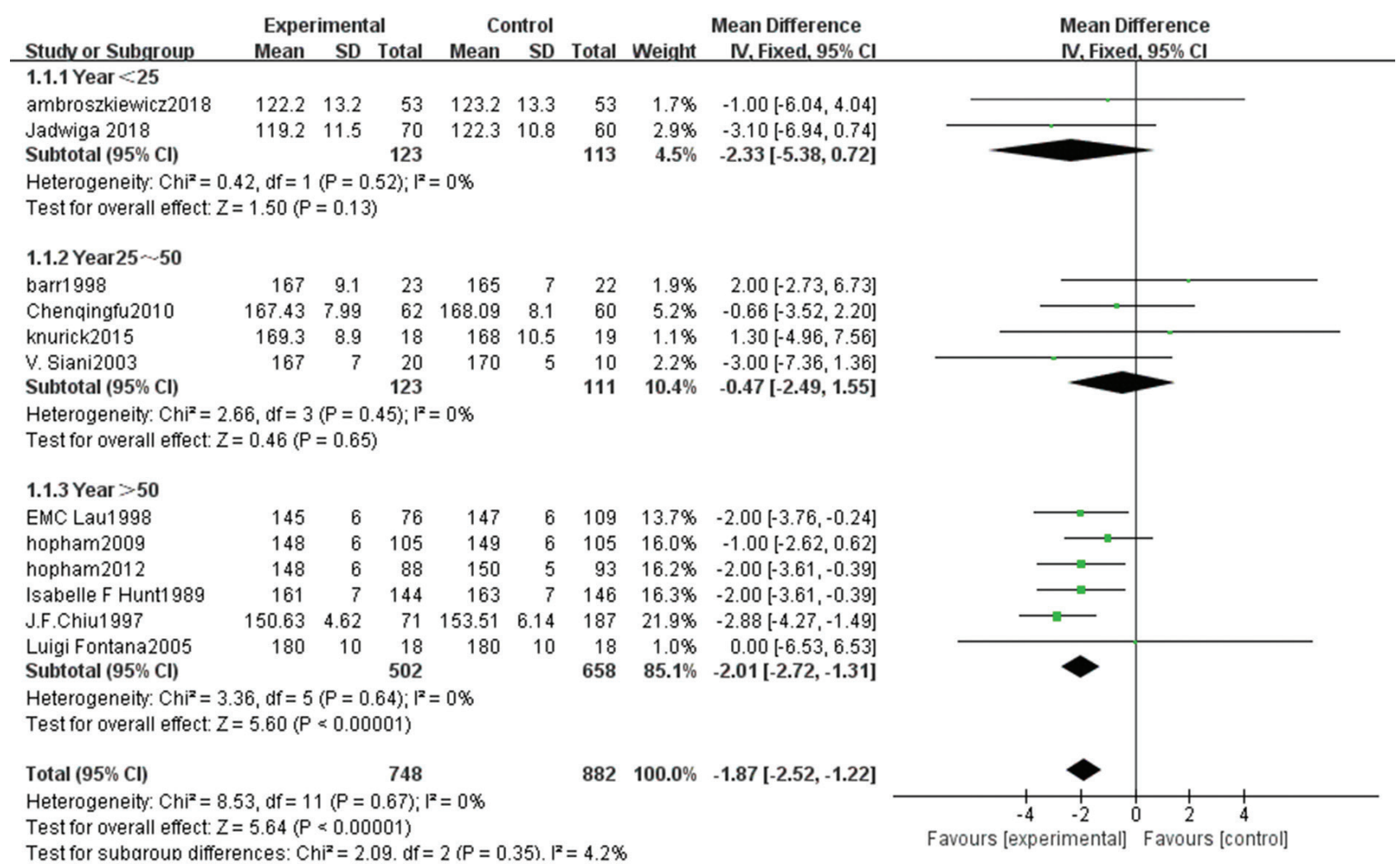

Fig. 5a. Meta-analysis of height between different age groups.

2) Sensitivity analysis revealed that the Hunt study (8) had a significant impact on the strength of the conclusion. After removing this study, the weight of the non-vegetarian group was still greater than the vegetarian group (mean difference: $-1.55,95 \% \mathrm{CI}$ : -2.45 to $-0.65, P=0.0008$ ). Heterogeneity analysis was carried out by removing small sample size and influencing sensitivity. After removing the Hunt (8), Fontana (13), Knurick (18), and Siani (12) studies, the heterogeneity was relatively low $\left(\chi^{2}=1.86\right.$, $\left.P=0.93, I^{2}=0 \%\right)$ and the weight of the non-vegetarian group was still greater than that of the vegetarian group (mean difference: $-0.98,95 \% \mathrm{CI}$ : -1.91 to $-0.04, P=0.04$ ).

3) According to subgroup analysis, compared with the age group, the weight of the non-vegetarian group 25-50 years of age was greater than the vegetarian group (mean difference: $-2.84,95 \% \mathrm{CI}:-5.13$ to -0.55 , $P=0.02$; subgroup difference: $\chi^{2}=1.37, P=0.51$, $I^{2}=0 \%$; Fig. $4 \mathrm{a}$ ), and based on regional comparison, the weight of the non-vegetarian group was equal to the vegetarian group (subgroup difference: $\chi^{2}=1.95, P=0.38, I^{2}=0 \%$; Fig. 4b).

Comparison of height between vegetarians and non-vegetarians
Twelve articles $(7-14,16-19,21)$ provided data on 1,630 cases, including 748 vegetarians and 882 non-vegetarians.

1) A heterogeneity test showed no statistical differences $\left(\chi^{2}=8.53, P=0.67, I^{2}=0 \%\right)$. Therefore, a fixed-effect model analysis was adopted, which indicated that the height of the non-vegetarian group was greater than that of the vegetarian group (Fig. 5; mean difference: $-1.87,95 \%$ CI: -2.52 to $-1.22, P<0.00001)$.

2) Sensitivity analysis revealed that the Chiu study (9) had a greater impact on the strength of the conclusion. After removing this study, the height of the non-vegetarian group was still greater than that of the vegetarian group (mean difference: $-1.59,95 \%$ CI: -2.32 to -0.85 , $P<0.0001)$. Heterogeneity analysis was carried out by removing small sample size and influencing sensitivity. After removing the Chiu (9), Fontana (13), Knurick (18), Barr (11), and Siani (12) studies, the heterogeneity was relatively low $\left(\chi^{2}=2.19, P=0.90, P=0 \%\right)$ and height of the non-vegetarian group was greater than that of the vegetarian group (mean difference: -1.70 , $95 \%$ CI: -2.47 to $-0.93, P<0.00001)$.

3) According to subgroup analysis, 1) based on a comparison of the age group, the height of the non-vegetarian group at 50 years of age was greater than that 


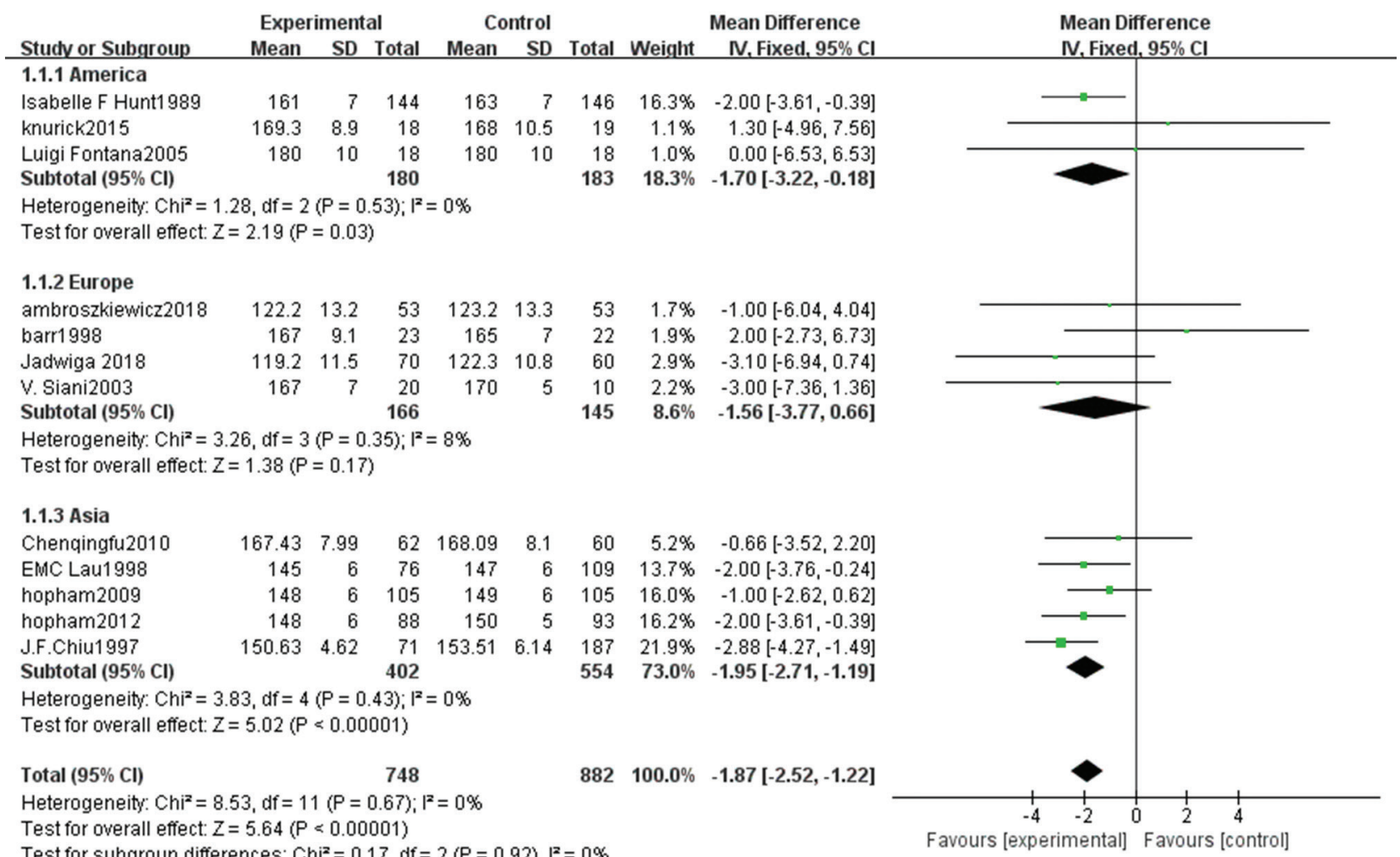

Test for subaroun differences: $\mathrm{Chi}^{2}=0.17$. df $=2(\mathrm{P}=0.92) \cdot \mathrm{I}^{2}=0 \%$

Fig. 5b. Meta-analysis of height between different populations.

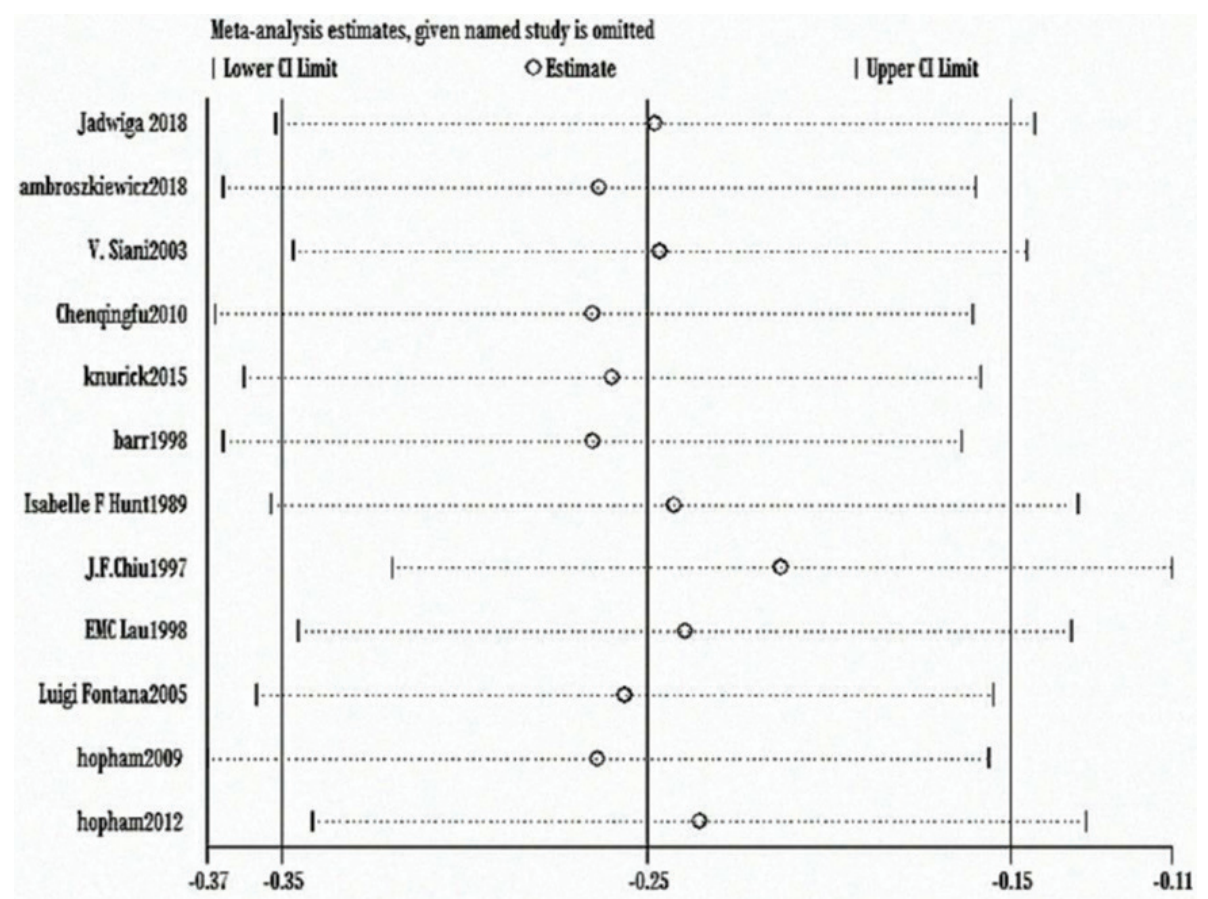

Fig. 5c. Sensitivity analysis of height.

of the vegetarian group (mean difference: -2.01, 95\% CI: -2.72 to $-1.31, P<0.00001$; subgroup difference: $\chi^{2}=2.09, P=0.35, I^{2}=4.2 \%$; Fig. 5a), and 2) based on regional comparison, the height of the non-vegetarian group was greater than that of the vegetarian group (mean difference: $-1.70,95 \% \mathrm{CI}:-3.22$ to -0.18 , 

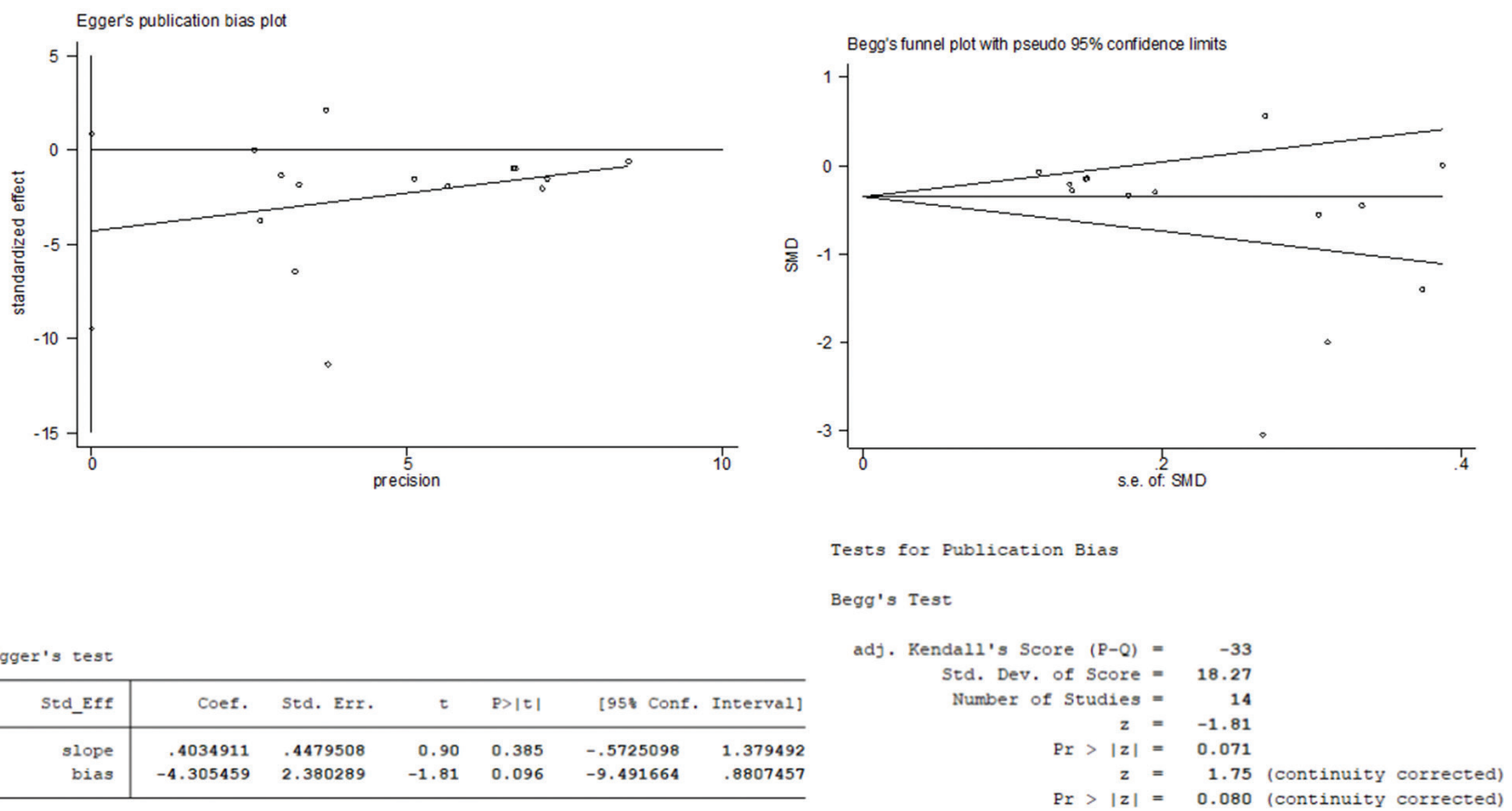

Fig. 6. Publication bias test in Egger's and Begg's tests.

$P=0.03$ ) in the American or Asian population (mean difference: $-1.95,95 \%$ CI: -2.71 to $-1.19, P<0.00001$; subgroup difference: $\chi^{2}=0.17, P=0.92, I^{2}=0 \%$; Fig. 5b).

\section{Publication bias}

Egger's and Begg's tests were performed to evaluate the publication bias. As shown in Fig. 6, the symmetry of the funnel plots suggested no obvious publication bias in Begg's test $(P>0.05)$, and the results of Egger's test suggested no evidence of publication bias $(P>0.05)$.

\section{Discussion}

\section{Advantages of vegetarian diet}

Diet and other lifestyle factors play an important role in the pathogenesis of chronic diseases $(22,23)$. A healthy lifestyle decreases the prevalence of coronary heart disease by $83 \%$ and decreases type II diabetes in women by $91 \%$ (24). A vegetarian diet, due to its unique natural ingredients and composition of nutrients, plays an important role in the prevention and treatment of metabolic disorders, including blood lipid disorders, obesity, type II diabetes, coronary heart disease, and metabolic syndrome.

Low-fat vegetarian and traditional diabetic diets result in no significant differences in weight improvement, but a vegetarian diet significantly reduces fasting blood glucose, cholesterol, and triglyceride levels in type II diabetic patients $(25,26)$. A variety of dietary patterns have shown that the systolic blood pressure level of those who opt for a vegetarian diet is significantly lower (27-29). A meta-analysis by Yokoyama et al. (30) also confirmed this finding. A study involving 55,459 Swedish women conducted by Newby et al. (31) showed that the prevalence of overweight or obesity was $40 \%$, whereas the serum total cholesterol, low-density lipoprotein (LDL), and triglycerides levels were significantly lower in vegetarians (32). Vegan and lacto-vegetarian diets reduce triglycerides and LDL by $10-15 \%$, vegetarian diets reduce triglycerides and LDL by $15-25 \%$, and combined diets (fiber, soy, and nuts added to vegan diets) reduce triglycerides and LDL by $20-35 \%$; for every $1 \%$ reduction in LDL, the risk of coronary heart disease is reduced by $1 \%$ (33). Therefore, the decreased mortality rate of coronary heart disease in the vegetarian population may be related to the lipid-lowering effect of a vegetarian diet. In addition, vegetarian diets are rich in vitamins and have strong antioxidant and free radical scavenging effects. Oxidative damage is closely related to metabolic syndrome. Vitamin E, together with superoxide dismutase and glutathione peroxidase, make up the antioxidant system in the body and remove free radicals. Vitamin $\mathrm{C}$ is transformed into dehydroascorbic acid through oxidation and reduction to remove oxygenand hydroxyl-free radicals to prevent oxidation-related diseases (34). As the helper factor and precursors of mitochondrial enzymes, B vitamins can protect or activate mitochondrial enzymes, thereby maintaining normal energy metabolism and preventing the occurrence of metabolic diseases (35). 


\section{Disadvantages of a vegetarian diet}

From the perspective of nutrition, there are also deficiencies in a vegetarian diet. Firstly, the quality of protein in plant food is poor (except soy protein), and the composition of essential amino acids is incomplete or the quantity of essential amino acids is insufficient. Secondly, a vegetarian diet does not contain vitamin B12 and most essential elements, such as iron and calcium, and zinc is very limited. Oxalic acid, phytic acid, dietary fiber, and the interference by other minerals prevent the absorption of calcium, zinc, and iron, thus causing iron, calcium, zinc, and fat-soluble vitamins (especially vitamin D) deficiencies (36). Therefore, it is necessary to increase the total amount of food in the diet to ensure adequate intake of nutrients and energy because women during special physiologic periods (such as pregnancy), patients and the elderly with limited appetite, and children are particularly vulnerable to energy or malnutrition.

In terms of population growth, infants with a precise vegetarian diet containing milk and dairy products exhibit normal growth and development, but among those following absolute vegetarian diets, heat energy, protein, calcium, iron, zinc, vitamin $\mathrm{D}$, riboflavin, and other $\mathrm{B}$ vitamins are inadequate, and thus are prone to a number of nutrient deficiencies. Iron stores get depleted 4-6 months after a baby is born, and the content of iron in milk becomes insufficient; thus, infants $>4$ months of age must absorb iron from meals, otherwise they will develop iron deficiency anemia. Children who are breastfed for 6 months or longer are prone to rickets when they are fed a vegan diet with minimal vitamin D after weaning. Pre-schoolers, 18 months to 5 years of age, who adopt an absolute vegetarian diet show slow growth and development, and were significantly shorter and weight less than children who eat a balanced diet (37-39). Puberty is the most vigorous period of growth. The requirement for nutrients increases greatly, and puberty is a period of increased sensitivity to nutrient deficiency. If teenagers adopt a vegetarian diet and the type and quantity of food is not designed properly, teenagers will face the risk of a series of nutrient deficiencies, especially calcium, thermal energy, iron, zinc, vitamins A and $\mathrm{D}$, and protein, which will seriously affect growth and development. The requirements for pregnant women and lactating mothers with respect to heat, calcium, vitamins A, C, and D, iron, and folic acid are greatly increased. Malnutrition during pregnancy can also cause intrauterine growth retardation, congenital malformations, and low body weight in the fetus $(39,40)$. Osteoporosis is the most common degenerative bone metabolic disease among the elderly, especially postmenopausal women, and is an important cause of pathologic fractures in the elderly. People who eat a vegetarian diet tend to be deficient in calcium, iron, vitamin D, and vitamin B12, and have low levels of protein and total fat, which can reduce bone density and increase the risk of fractures $(41,42)$.

\section{Healthy bone diet}

In recent years, the relationship between dietary patterns and bone health has received increasing attention (43). According to a study of people aged 20-25, five dietary patterns (healthy, traditional, refined, society, rich in nuts and meat products), adhere to nuts and a meat-eating pattern in women is associated with a higher bone mineral density and bone mineral content (44). Another study reported that a diet rich in milk and dairy was better for bone health than other diets (45). Vegetables and fruits in vegetarian diets are rich in minerals (such as calcium, potassium, magnesium, phytocarotene, vitamin, and phytochemicals [such as phytoestrogens]) and many other nutrients that can affect calcium absorption or bone reconstitution (46-48).

The 2015-2020 dietary guidelines for US residents were issued in January 2016 and recommended healthy eating patterns, including more vegetables, fruits, whole grains, low-fat dairy products, nuts, and seafood and less red and processed meats, sugar-sweetened beverages, salt, and refined carbohydrates, and limit cholesterol intake (49).

\section{Conflicts of interest and funding}

The authors have not received any funding or benefits from any industry or elsewhere to conduct this study.

\section{References}

1. Pickett-Blakely O. Obesity and irritable bowel syndrome: a comprehensive review [J]. Gastroenterol Hepatol 2014; 10(7): 411. PMID: 25904828, PMCID: PMC4302488.

2. Willett WC, Sacks F, Trichopoulou A, Drescher G, Ferro-Luzzi A, Helsing E, et al. Mediterranean diet pyramid: a cultural model for healthy eating [J]. Am J Clin Nutr 1995; 61(6 Suppl): 1402S. PMID: 7754995. doi: 10.1093/ajcn/61.6.1402S

3. Salas-Salvadó J, Bulló M, Babio N, Martínez-González MÁ, Ibarrola-Jurado N, Basora J, et al. Reduction in the incidence of type 2 diabetes with the Mediterranean diet: results of the PREDIMED-Reus nutrition intervention randomized trial [J]. Diabetes Care 2011; 34(1): 14-19. PMID: 20929998, PMCID: PMC3005482. doi: 10.2337/dc10-1288

4. Clarys P, Deliens T, Huybrechts I, Deriemaeker P, Vanaelst B, De Keyzer W, et al. Comparison of nutritional quality of the vegan, vegetarian, semi-vegetarian, pesco-vegetarian and omnivorous diet [J]. Nutrients 2014; 6(3): 1318-32. PMID: 24667136, PMCID: PMC3967195. doi: 10.3390/nu6031318

5. Rizzo NS, Jaceldo-Siegl K, Sabate J, Fraser GE. Nutrient profiles of vegetarian and nonvegetarian dietary patterns [J]. J Acad Nutr Diet 2013; 113(12): 1610-19. PMID: 23988511, PMCID: PMC4081456. doi: 10.1016/j.jand.2013.06.349

6. Farmer B, Larson BT, Fulgoni VL, Rainville AJ, Liepa GU. A vegetarian dietary pattern as a nutrient-dense approach to weight management: an analysis of the national health and nutrition examination survey 1999-2004 [J]. J Am Diet 
Assoc 2011; 111(6): 819-27. PMID: 21616194 doi: 10.1016/j. jada.2011.03.012

7. von Elm E, Altman DG, Egger M, Pocock SJ, Gøtzsche PC, Vandenbroucke JP, et al. The strengthening the reporting of observational studies in epidemiology (STROBE) statement: guidelines for reporting of observational studies [ J]. Internist (Berl) 2008; 49(6): 688-93. PMID: 25046131. doi: 10.1016/j. ijsu.2014.07.013

8. Hunt IF, Murphy NJ, Henderson C, Clark VA, Jacobs RM, Johnston $\mathrm{PK}$, et al. Bone mineral content in postmenopausal women comparison of omnivores and vegetarians [J]. Am J Clin Nutr 1989; 50(5): 17-23. PMID: 2773831. doi: 10.1093/ajcn/50.3.517

9. Chiu JF, Lan SJ, Yang CY, Wang PW, Yao WJ, Su LH, et al. Long-term vegetarian diet and bone mineral density in postmenopausal Taiwanese women [J]. Calcif Tissue Int 1997; 60(3): 245. PMID: 9069160 . doi: 10.1007/p100005812

10. Lau EM, Kwok T, Woo J, Ho SC. Bone mineral density in Chinese elderly female vegetarians, vegans, lacto-vegetarians and omnivores [J]. Eur J Clin Nutr 1998; 52(1): 60-4. PMID: 9481534. doi: 10.1038/sj.ejcn.1600516

11. Barr SI, Prior JC, Janelle KC, Lentle BC. Spinal bone mineral density in premenopausal vegetarian and nonvegetarian women: cross-sectional and prospective comparisons [J]. J Am Diet Assoc 1998; 98(7): 760-5. PMID: 9664916. doi: 10.1016/ S0002-8223(98)00172-2

12. Siani V, Mohamed EI, Maiolo C, Di Daniele N, Ratiu A, Leonardi A, et al. Body composition analysis for healthy Italian vegetarians [J]. Acta Diabetol 2003; 40: S297-8. PMID: 14618498. doi: 10.1007/s00592-003-0091-1

13. Fontana L, Shew JL, Holloszy JO, Villareal DT. Low bone mass in subjects on a long-term raw vegetarian diet [J]. Arch Intern Med 2005; 165(6): 684-9. PMID: 15795346. doi: 10.1001/ archinte.165.6.684

14. Ho-Pham LT, Nguyen PL, Le TT, Doan TA, Tran NT, Le TA, et al. Veganism, bone mineral density, and body composition: a study in Buddhist nuns [J]. Osteoporos Int 2009; 20(12): 2087-93. PMID: 19350341. doi: 10.1007/s00198-009-0916-Z

15. Sambol SZ, Stimac D, Orlić ZC, Guina T. Haematological, biochemical and bone density parameters in vegetarians and non-vegetarians [J]. West Indian Med J 2009; 58(6): 512. PMID: 20583676.

16. Chen QF, Yang SY, Yan B, Liu CQ, Shi XL, Zhang HJ, et al. Comparative analysis of bone mineral density and osteoporosis in vegetarian and non-vegetarian diet [J]. J Jilin Univ 2010; 36(4): 794-6. doi: 10.3760/cma.j.issn.0254-6450.2014.03.021

17. Ho-Pham LT, Vu BQ, Lai TQ, Nguyen ND, Nguyen TV. Vegetarianism, bone loss, fracture and vitamin $\mathrm{D}$ : a longitudinal study in Asian vegans and non-vegans [J]. Eur J Clin Nutr 2012; 66(1): 75-82. PMID: 21811293. doi: 10.1038/ejen.2011.131

18. Knurick JR, Johnston CS, Wherry SJ, Aguayo I. Comparison of correlates of bone mineral density in individuals adhering to lacto-ovo, vegan, or omnivore diets: a cross-sectional investigation [J]. Nutrients 2015; 7(5): 3416-26. PMID: 25970147, PMCID: PMC4446759. doi: 10.3390/nu7053416

19. Movassagh EZ, Adg BJ, Kontulainen S, Whiting S, Szafron M, Vatanparast H. Vegetarian-style dietary pattern during adolescence has long-term positive impact on bone from adolescence to young adulthood: a longitudinal study [J]. Nutr J 2018; 17(1): 36. PMID: 29490662, PMCID: PMC6389064. doi: 10.1186/ s12937-018-0324-3

20. Ambroszkiewicz J, Chełchowska M, Szamotulska K, Rowicka G, Klemarczyk W, Strucińska M, et al. The assessment of bone regulatory pathways, bone turnover, and bone mineral density in vegetarian and omnivorous children [J]. Nutrients 2018; 10(2): pii: E183. PMID: 29414859, PMCID: PMC5852759. doi: 10.3390/nu10020183

21. Ambroszkiewicz J, Chełchowska M, Szamotulska K, Rowicka G, Klemarczyk W, Strucińska M, et al. Bone status and adipokine levels in children on vegetarian and omnivorous diets [J]. Clin Nutr 2019; 38(2): 730-7. PMID: 29609869. doi: 10.1016/j. clnu.2018.03.010

22. Kushi LH, Doyle C, McCullough M, Rock CL, DemarkWahnefried W, Bandera EV, et al. American cancer society guidelines on nutrition and physical activity for cancer prevention: reducing the risk of cancer with healthy food choices and physical activity [J]. CA Cancer J Clin 2012; 62(1): 30-67. PMID: 11929008. doi: 10.3322/canjclin.52.2.92

23. Lichtenstein AH, Appel LJ, Brands M, Carnethon M, Daniels $\mathrm{S}$, Franch HA, et al. Diet and lifestyle recommendations revision 2006 a scientific statement from the American Heart Association Nutrition Committee [J]. Circulation 2006; 114(1): 82. PMID: 16785338. doi: 10.1161/CIRCULATIONAHA.106.176158

24. Rimm EB, Stampfer MJ. Diet, lifestyle, and longevity - the next steps? [J]. J Am Med Assoc 2004; 292(12): 1490. PMID: 15383521. doi: 10.1001/jama.292.12.1490

25. Barnard ND, Katcher HI, Jenkins DJ, Cohen J, TurnerMcGrievy G. Vegetarian and vegan diets in type 2 diabetes management [J]. Nutr Rev 2009; 67(5): 255-63. PMID: 19386029. doi: $10.1111 / j .1753-4887.2009 .00198 . x$

26. Barnard ND, Cohen J, Jenkins DJA, Turner-McGrievy G, Gloede L, Green A, et al. A low-fat vegan diet and a conventional diabetes diet in the treatment of type 2 diabetes: a randomized, controlled, 74-wk clinical trial [J]. Am J Clin Nutr 2009; 89(5): 1588S-96S. PMID: 19339401, PMCID: PMC2677007. doi: 10.3945/ajcn.2009.26736H

27. Rouse IL, Armstrong BK, Beilin LJ. The relationship of blood pressure to diet and lifestyle in two religious populations [J]. J Hypertens 1983; 1(1): 65-71. PMID: 6681026.

28. Melby CL, Lyle RM, Poehlman ET. Blood pressure and body mass index in elderly long-term vegetarians and nonvegetarians [J]. Nutr Rep Int 1988; 37: 47-55. PMID: 8409080. doi: 10.1080/07315724.1993.10718308

29. Rouse IL, Beilin LJ, Armstrong BK, Vandongen R. Blood-pressure-lowering effect of a vegetarian diet: controlled trial in normotensive subjects [J]. Lancet 1983; 1(8314-8315): 5-10. PMID: 6129380. doi: 10.1016/s0140-6736(83)91557-x

30. Yokoyama Y, Nishimura K, Barnard ND, Takegami M, Watanabe M, Sekikawa A, et al. Vegetarian diets and blood pressure: a meta-analysis [J]. JAMA Intern Med 2014; 174(4): 577-87. PMID: 24566947. doi: 10.1001/jamainternmed.2013.14547

31. Newby PK, Tucker KL, Wolk A. Risk of overweight and obesity among semivegetarian, lactovegetarian, and vegan women [J]. Am J Clin Nutr 2005; 81(6): 1267-74. PMID: 15941875. doi: 10.1093/ajcn/81.6.1267

32. De Baise SG, Fernandes SF, Gianni RJ, Duarte JL. Vegetarian diet and cholesterol and triglyceride levels [J]. Arq Bras Cardiol 2007; 88(1): 35-39. PMID: 17364116. doi: 10.1590/ s0066-782x2007000100006

33. Grundy SM, Cleeman JI, Merz CN, Brewer HB Jr, Clark LT, Hunninghake DB, et al. Implications of recent clinical trials for the National Cholesterol Education Program Adult Treatment Panel III guidelines [J]. Circulation 2004; 110(2): 227-39. PMID: 15358046. doi: 10.1016/j.jacc.2004.07.001

34. Ginter E, Simko V, Panakova V. Antioxidants in health and disease [J]. Bratisl Lek Listy 2014; 115(10): 603-6. PMID: 25573724. doi: 10.4149/bll_2014_116 
35. Liu J, Shen W, Zhao B, Wang Y, Wertz K, Weber P, et al. Targeting mitochondrial biogenesis for preventing and treating insulin resistance in diabetes and obesity: hope from natural mitochondrial nutrients [J]. Adv Drug Deliv Rev 2009; 61(14): 1343-52. PMID: 19716392. doi: 10.1016/j.addr.2009.06.007

36. Ness AR, Powles JW. Fruit and vegetables, and cardiovascular disease: a review [J]. Int J Epidemiol 1997; 26(1): 1. doi: 10.1093/ ije/26.1.1

37. Dwyer JT, Dietz Wh Jr, Andrews EM. Nutritional status of vegetarian child ren. Am J Clin Nutr 1982; 35: 204. PMID: 7064883. doi: 10.1093/ajcn/35.2.204

38. Wei S. Food, nutrients and osteoporosis prevention [J]. Chinese Gen Med 2014; 17(9): 971-9. PMID: 7064883. doi: 10.1093/ ajen/35.2.204

39. Yunhua D. The pros and cons of a vegetarian diet [J]. Chinese Food Nutr 2006; (8): 54-6. doi: 10.3760/cma.j.i ssn.0254-6450.2014.03.021

40. Junmei Y, Xiaoyi D. Effects of early and late pregnancy eating patterns on growth indicators of very low birth weight infants [J]. J Pediatr 2014; (8): 13-16. doi: 10.13407/j.cnki. jpp.1672-108X.2014.08.004

41. Wengreen HJ, Munger RG, West NA. Dietary protein in take an d risk of osteoporotic hip fracture in elderly residents of Utah [J]. J Bone Miner Res 2004; 19(4): 537-45. PMID: 15005839. doi: 10.1359/JBMR.040208

42. Kato I, Toniolo P, Zeleniuch-Jacquotte A, Shore RE, Koenig KL, Akhmedkhanov A, et al. Diet, smoking and anthropometrie indices and postmenopausal bone fractures: a prospective study [J]. Int J Epidemiol 2000; 29(1): 85-92. PMID: 10750608. doi: 10.1093/ije/29.1.85

43. Kontogianni MD, Yiannakouris N. Diet and bone health-the perspective of dietary pattern analysis [J]. Eur Musculoskelet Rev 2009; 4(1): 73-4.

44. Whittle CR, Woodside JV, Cardwell CR, McCourt HJ, Young IS, Murray LJ, et al. Dietary patterns and bone mineral status in young adults: the Northern Ireland Young Hearts Project [J]. Br J Nutr 2012; 108(8): 1494-504. PMID: 22214826. doi: 10.1017/ S0007114511006787

45. Shin S, Hong K, Kang SW, Joung H. A milk and cereal dietary pattern is associated with a reduced likelihood of having a lowbone mineral density of the lumbar spine in Korean adolescents [J]. Nutr Res 2013; 33(1): 59-66. PMID: 23351411. doi: 10.1016/j.nutres.2012.11.003

46. Prynne CJ, Mishra GD, O’Connell MA, Muniz G, Laskey MA, Yan $\mathrm{L}$, et al. Fruit and vegetable intakes and bone mineral status: a cross-sectional study in 5 age and sex cohorts $[\mathrm{J}]$. Am $\mathrm{J}$ Clin Nutr 2006; 3(6): 1420-8. PMID: 16789345. doi: 10.1093/ ajcn/83.6.1420

47. McGartland CP, Robson PJ, Murray LJ, Cran GW, Savage MJ, Watkins DC, et al. Fruit and vegetable consumption and bone mineral density: the Northern Ireland Young Hearts Project [J]. Am J Clin Nutr 2004; 80(4):1019-23. PMID: 15447914. doi: 10.1093/ajcn/80.4.1019

48. Sugiura M, Nakamura M, Ogawa K, Ikoma Y, Ando F, Yano $\mathrm{M}$. Bone mineral densityin post-menopausal female subjects is associated with serum antioxidant carotenoids [J]. Osteoporos Int 2008; 19(2): 211-19. doi: 10.1007/s00198-007-0457-2

49. 2015-2020 Dietary guidelines for Americans (eighth edition) [EB /OL]. (2016-01-07) [2017-06-10]. [cited 10 March 2019]. Available from: https://health.gov/dietaryguidelines/2015/ guidelines/

\section{*Jianjun Wang}

Department of Spine and Osteology

Zhuhai People's Hospital (Zhuhai Hospital Affiliated with Jinan University)

79 Kangning Road, Zhuhai 519000 , China

Email: jun_wj@aliyun.com 